\title{
REFORMA FISCAL 2020: IVA E ISR PARA EFECTOS DE PLATAFORMAS DIGITALES
}

\section{FISCAL REFORM 2020: VAT AND ISR FOR THE PURPOSES OF DIGITAL PLATFORMS}

C. Samantha Cortés González ${ }^{\text {a }}$

Dr. René Mariani Ochoa ${ }^{\text {b }}$

${ }^{a}$ Universidad Veracruzana

Facultad de Contaduría y Administración samat.cg.27@gmail.com

${ }^{\mathrm{b}}$ Universidad Veracruzana Instituto de Investigaciones en Contaduría rmariani@uv.mx

\section{RESUMEN}

En esta investigación lo que se busca es explicar en qué consiste una de las reformas fiscales 2020, explicando primeramente conceptos básicos para una mayor comprensión.

Esta reforma afecta los impuestos de valor agregado y el impuesto sobre la renta ya que ahora se gravará a plataformas digitales, las cuales los últimos años han tenido un enorme crecimiento.

Primeramente, se explica qué entendemos como plataforma digital, los tipos de plataformas digitales que existen y un poco del término comercio electrónico o ecommerce, ya que los dos vienen de la mano para llevar a cabo una economía digital.

También conceptualizamos los impuestos, para recordar qué son, conocer porqué la federación los cobra y sus sustentos legales.

Posteriormente, llegamos a la parte central de la investigación, abordamos por separado la afectación de esta reforma a los dos diferentes impuestos; mostrando, resumiendo y explicando cada parte de las secciones añadidas a cada ley. 
PALABRAS CLAVE: Plataformas digitales; Comercio electrónico; Servicios digitales;

Economía digital; Impuestos.

\section{ABSTRACT}

The aim of this research is to explain what one of the 2020 tax reforms consists of, firstly explaining basic concepts for a better understanding.

This reform affects value added taxes and income tax since it will now be taxed on digital platforms, which have had enormous growth in recent years.

First, we explain what we understand as digital platform, the types of digital platforms that exist and a bit of the term e-commerce, since the two come together to carry out a digital economy.

We also conceptualize the taxes, to remember what they are, to know why the federation charges them and their legal sustenance.

Later, we arrive at the central part of the investigation, we approach separately the affectation of this reform to the two different taxes; showing, summarizing and explaining each part of the sections added to each law.

KEYWORDS: Digital plataforms; E-commerce; Digital services; Digital economy; Taxes. 


\section{INTRODUCCIÓN}

En los últimos años el mundo de los negocios ha experimentado algunos cambios importantes en cuanto a procesos comerciales y organización de las empresas. Las oportunidades de las empresas y de los consumidores han ido en aumento gracias a las posibilidades que el comercio ofrece a través de Internet, centrándonos en lo que hoy en día denominamos comercio electrónico o e-commerce. El comercio electrónico permite a las empresas ser más flexibles con sus operaciones internas y dar mejor servicio a los clientes. Este fenómeno ha sido toda una revolución tecnológica.

Por otra parte, las empresas que perciben ingresos de las prestación de bienes y servicios mediante plataformas digitales no pagaban impuestos en México, fue hasta 2020 en donde una reforma fiscal creaba en la Ley del Impuesto al Valor Agregado la sección "De la prestación de servicios digitales por residentes en el extranjero sin establecimiento en México" y en la Ley del Impuesto Sobre la Renta la sección III: "De los ingresos por la enajenación de bienes o la prestación de servicios a través de Internet, mediante plataformas tecnológicas, aplicaciones informáticas y similares".

Este trabajo se hace con la finalidad de exponer al lector una manera más fácil de entender y comprender una importante reforma fiscal de la cual sin duda es importante conocer porqué el comercio electrónico es un medio que irá tomando un importante papel en la manera en que adquirimos bienes y servicios cada día más personas. Más negocios y empresas se han ido involucrando a esta alternativa de negocio. La presente investigación se realizó mediante una metodología análisis-síntesis en donde se hizo la separación y estudio independiente de cada una de las partes del trabajo y en fragmentos se fue contestando cada una de las partes al final en una conclusión general.

La separación de ideas o conceptos es lo que nos permite su comprensión plena, es decir, mediante un proceso cognoscitivo donde se aprecian todos los puntos que los hacen coincidir o concordar. Posteriormente se realiza la síntesis de estas ideas, es la reunión propia de cada una de las separaciones hechas con anterioridad y esto nos permite entender la concordancia de las ideas, esto lleva a poner en jerarquías cada una de las partes señaladas y con esto llegamos a la conclusión que es el resultado final del estudio realizado 
y que se presente más adelante.

El objetivo de esta investigación es que el lector pueda entender en primer lugar el origen del comercio electrónico, conocer lo que significa, cómo es que se integra y cómo es que forma parte de nuestro día a día; por otra parte, se explica el gran paso que dio nuestro país al integrar las plataformas digitales al cobro de los impuestos ya que se estima una recaudación de 100 mil mdp solo en este ramo, y finalmente como se hará esta recaudación.

\section{FUNDAMENTACIÓN TEÓRICA.}

Por comercio internacional se entiende que es toda aquella actividad comercial de bienes y servicios entre países y mercados mundiales. Para esto Comercio y Aduanas de México (2019) nos dice que "El comercio internacional hace referencia a todas las actividades comerciales que tienen que ver con la transferencia de bienes, recursos, ideas, tecnologías y servicios a través de los distintos países y sus mercados (forma parte de la economía)".

El comercio internacional se divide en: la exportación y la importación. Por exportación entendemos que es "la venta de bienes y servicios fuera del territorio nacional. El envío de nuestros productos y servicios a cualquier otro lugar del mundo fuera de nuestras fronteras con fines comerciales" IEBS (2019), así mismo la importación según IEBS (2019) se define como: "la compra y venta de bienes y servicios extranjeros para el uso y consumo en un país o territorio o bien para su elaboración posterior".

Este tipo de comercio va de la mano de la economía digital donde en conjunto ofrecen los llamados servicios digitales, estos servicios son suministrados de manera on-line a través de internet y solo pueden ser tomados mediante el uso de dispositivos digitales como celulares, computadoras y tablets, entre otros, muchas veces se apoyan del uso de plataformas digitales como aplicaciones y paginas web. 
Actualmente y gracias a la globalización podemos tener una respuesta a nuestras necesidades, a través de un dispositivo en el cual con una aplicación móvil pedimos comida, taxi, reservamos hospedaje, descargamos música, libros y además transferimos efectivo. Todo gracias a las plataformas de servicios digitales contenidos en nuestro Smartphone.

Tomemos en cuenta que una plataforma de servicio digital y la venta de productos en el ciberespacio no es lo mismo si estos últimos ocupan la web para tener contacto con la persona que ofrece el servicio y posteriormente este se hace frente a frente.

Para entender mejor esto, Pendino (2018), nos dice que "Una PSD es de aquella que presta de manera online al usuario y que éste sólo puede utilizar a través de un dispositivo digital (computadora, teléfono inteligente, Tablet, etc.)"; por otra parte, Giraldo (2019) explica que para ella "Las plataformas digitales son soluciones online que posibilitan la ejecución de diversas tareas en un mismo lugar a través de internet."

\section{1 Clasificación de servicios digitales y del comercio electrónico.}

A lo largo del tiempo los servicios digitales han ido evolucionando, esto nos permite poder ir clasificándolos y una manera de hacerlo es por medio de su orientación, a continuación, se hablará los múltiples servicios digitales de la siguiente forma:

\section{Figura 1}

Clasificación de servicios digitales 


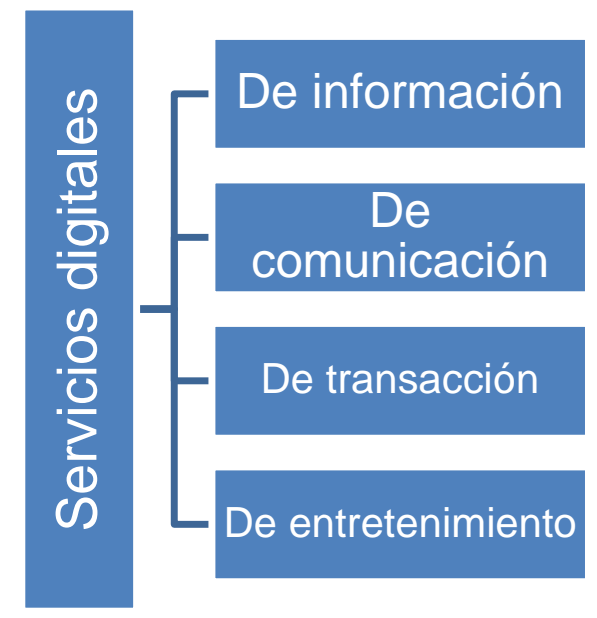

Fuente: Elaboración propia (2020).

A continuación, se hablará los múltiples servicios digitales de la siguiente forma:

\section{- Información:}

Gran parte de los servicios que se prestan a través de la web se ubican en esta clasificación, Abadal (2001) nos dice que los servicios digitales de información: "consisten en ofrecer, normalmente a través de bases de datos documentales, la posibilidad de acceder a grandes volúmenes de información retrospectiva o en tiempo real de todos los ámbitos del conocimiento y de todas las actividades sociales."

- Comunicación:

Desde los principios del internet este rubro ha estado presente con el correo electrónico, con el tiempo otros medios de comunicación se han ido creando con nuevas maneras de estar conectados con los demás. Se trata de un servicio muy utilizado y en continuo crecimiento que, con los años, ha adquirido carácter de servicio universal.

\section{- Transacciones:}

La tercera clasificación consiste en autorizar pagos o transacciones a través del sistema. En este sentido, podemos encontrar diversos proveedores especializados en gestión de cuentas bancarias estos nos permiten comprar todo tipo de productos, hacer reservas de hoteles, 
líneas aéreas, pedir alimentos, transportes, etc. Y el importe de estos son cargados a la cuenta del cliente.

- $\quad$ Entretenimiento:

Aquí entran aquellos servicios con el fin de distraer al usuario ya sea un servicio de streaming de música o películas, servicios de videojuegos, etc. Esta clasificación es una de las populares en los últimos 5 años.

\section{2 Marco jurídico del comercio electrónico en México}

En materia normativa, en México el comercio electrónico se rige de un compendio de leyes que permiten llevar a cabo la relación comercial. Para llevar a cabo este negocio a nivel internacional tenemos que conocer que los países tienen normativa convenida y es necesario apegarse a esta.

Actualmente, en México tenemos un marco legal a seguir para el comercio electrónico, los principales mediadores son: el sistema financiero y la red de telecomunicaciones. Las siguientes leyes y códigos también rigen esta actividad económica:

- $\quad$ Ley Federal de Telecomunicaciones.

- $\quad$ Ley Federal de Protección al Consumidor.

- $\quad$ Código de Comercio.

- Código Civil Federal

- $\quad$ Código Fiscal de la Federación.

- $\quad$ Ley Federal de los Derechos de Autor.

- $\quad$ Ley de Propiedad Industrial.

Aunque, los más importantes son: el Código de Comercio y el Código Civil ya que estos ayudan en la regulación de las operaciones comerciales e intercambio de datos e información que se llevan a cabo por medios electrónicos. Dos órganos reguladores en el e- 
commerce son:

- $\quad$ Procuraduría Federal del Consumidor, PROFECO.

- Instituto Mexicano de la Propiedad Industrial, IMPI.

\section{3 Servicios Digitales para efectos de IVA e ISR.}

Servicios Digitales para efectos de Impuesto al Valor Agregado

Actualmente existen en el país más de 800,000 contribuyentes prestando un servicio en una plataforma digital ya sea de servicio de transporte, entrega de alimentos u hospedaje, entre otros. A partir del 1 de junio de 2020 esta reforma entró en vigor y los usuarios de las plataformas digitales deberán pagar impuestos que fueron aprobados en los paquetes fiscales 2020 .

En este capítulo hablaremos de los contribuyentes que ofrecen productos o servicios por medio de una plataforma digital residentes en México o en el extranjero y que tendrán que pagar dicho impuesto.

Prestadores de servicios digitales con residencia en México

Se considera residente en México cuando los receptores están ubicados en territorio nacional, para entenderlo mejor el Art. 1 A-BIS de la ley del IVA nos menciona:

Artículo 1o.-A BIS. - Los contribuyentes residentes en México que proporcionen los servicios digitales a que se refiere la fracción II del artículo 18-B de la presente Ley a receptores ubicados en territorio nacional, que operen como intermediarios en actividades realizadas por terceras afectas al pago del impuesto al valor agregado...

Así mismo, el artículo anterior determina que pagaran el impuesto aquellos contribuyentes que ofrezcan los servicios a los que se refiere la fracción II del art. 18-B:

Artículo 18-B.- ...Se consideran únicamente los servicios digitales que a contin\{uación se mencionan: 
II. Los de intermediación entre terceros que sean oferentes de bienes o servicios y los demandantes de los mismos.

De igual manera el IVA, mencionado anteriormente es de una tasa del $16 \%$, aunque tenemos que aclarar que la retención que realice el contribuyente va a variar:

- Los inscritos como personas físicas con actividad empresarial: Se les hará una retención automática del 3 al 9\% de ISR y el 8\% del IVA.

- Los que estén dados de alta como Régimen de Incorporación Fiscal o RIF: Tendrán la retención de impuestos de manera opcional, tendrán que informar si quieren que la plataforma tecnológica les retenga el impuesto o realizar las declaraciones por su cuenta.

- RIF que realizan otras actividades fuera de la plataforma: De la misma manera que al primer caso se les hará la retención de manera automática.

Prestadores de servicios digitales con residentes en el extranjero sin establecimiento en México

Para efectos de este tema, según el artículo 16 en su cuarto párrafo considera que un residente en el extranjero prestador de servicios digitales debe pagar el impuesto a la federación mexicana cuando:

Art. 16.- Tratándose de los servicios digitales a que se refiere el artículo 18-B de esta Ley, prestados por residentes en el extranjero sin establecimiento en México, se considera que el servicio se presta en territorio nacional cuando el receptor del servicio se encuentre en dicho territorio...

Cuando el contribuyente cumpla lo anterior, entonces deberá considerar lo indicado en el Capítulo III BIS: "De la prestación de servicios digitales por residentes en el extranjero sin establecimiento en México". 


\section{Disposiciones generales.}

En primer lugar, según el artículo 18-B se consideran únicamente los servicios digitales que a continuación se mencionan:

- La descarga o acceso a imágenes, películas, texto, información, video, audio, música, juegos, incluyendo los juegos de azar, así como otros contenidos multimedia, ambientes multijugador, la obtención de tonos de móviles, la visualización de noticias en línea, información sobre el tráfico, pronósticos meteorológicos y estadísticas. Por ejemplo: Netflix, Spotify, Deezer, iTunes, etc.

- Con la excepción de la descarga o acceso a libros, periódicos y revistas electrónicos.

- Los de intermediación entre terceros que sean oferentes de bienes o servicios y los demandantes de los mismos. Con excepción de cuando se trate de servicios de intermediación que tengan por objeto la enajenación de bienes muebles usados.

- Clubes en línea y páginas de citas.

- La enseñanza a distancia o de test o ejercicios.

Por otro lado, tenemos que saber cuándo se considerará que el receptor del servicio se encuentra en el territorio nacional, esto lo explica el artículo 18-C: si el receptor manifiesta al prestador del servicio un domicilio ubicado en territorio nacional; cuando el receptor del servicio realice el pago al prestador del servicio mediante un intermediario ubicado en territorio nacional, o cuando la dirección IP que utilicen los dispositivos electrónicos del receptor del servicio corresponda al rango de direcciones asignadas a México o también si el receptor haya manifestado al prestador del servicio un número de teléfono cuyo código de país corresponda a México, cuando cumpla con cualquiera de los supuestos anteriores será obligado al pago del impuesto.

También hay que conocer las obligaciones que deben cumplir los residentes en el extranjero sin establecimiento en México que proporcionen servicios digitales a receptores ubicados en territorio: 
- Deberá inscribirse al Registro Federal del Contribuyente ante el SAT, dentro de los 30 días naturales siguientes contados a partir de la fecha en que se proporcionen por primera vez los servicios digitales a un receptor ubicado en territorio nacional.

- Ofertar y cobrar, conjuntamente con el precio de sus servicios digitales, el impuesto al valor agregado correspondiente en forma expresa y por separado.

- Proporcionar al SAT la información sobre el número de servicios u operaciones realizadas en cada mes de calendario con los receptores ubicados en territorio nacional que reciban sus servicios, clasificadas por tipo de servicios u operaciones y su precio. Deberá presentar esta información de manera trimestral, mediante una declaración electrónica a más tardar el 17 de cada mes.

- Calcular en cada mes de calendario el IVA correspondiente, aplicando la tasa del 16\% a las contraprestaciones efectivamente cobradas en dicho mes.

- Emitir y enviar vía electrónica a los receptores de los servicios digitales en territorio nacional los comprobantes correspondientes al pago de las contraprestaciones con el impuesto trasladado en forma expresa y por separado.

- Designar ante el SAT cuando se lleve a cabo el registro de RFC, un representante legal y proporcionar un domicilio en territorio nacional para efectos de notificación y vigilancia del cumplimiento de las obligaciones fiscales.

- Tramitar una firma electrónica avanzada.

Aunque el contribuyente cumpla con todas las obligaciones anteriores, no dará lugar a que se considere que el residente en el extranjero constituye un establecimiento permanente en México. Existe la posibilidad de que se podrá acreditar el impuesto que les sea trasladado en forma expresa y por separado, siempre que cumplan con los requisitos que establece la ley del IVA, con la excepción de los CFDI (Comprobantes Fiscales Digitales por Internet), para estos los comprobantes deberán reunir, al menos, los requisitos que anteriormente se 
mencionaron.

Cuando los servicios digitales a que se refiere el artículo 18-B se ofrezcan de manera conjunta con otros servicios digitales no contemplados en dicho artículo, el impuesto al valor agregado se calculará aplicando la tasa del 16\% únicamente a los servicios que si son considerados, pero el comprobante tiene que hacer la separación de dichos servicios y que las contraprestaciones correspondientes a cada servicio correspondan a los precios que se hubieran cobrado de no haberse proporcionado los servicios en forma conjunta. Cuando no se haga esta separación se entenderá que corresponde a un $70 \%$ de los montos, pero solo de los servicios que considera el artículo 18-B.

El Servicio de Administración Tributaria dará a conocer en su página de Internet y en el Diario Oficial de la Federación la lista de los residentes en el extranjero que se encuentren registrados en el mismo, en caso de que no se encuentren en esta lista dichos servicios se considerarán como importación.

Servicios digitales de intermediación entre terceros.

Un servicio con intermediación es aquel que necesita de trasladar el recurso al prestamista final, estos aparte de las obligaciones indicadas en la Sección I del Capítulo III BIS tienen que cumplir las siguientes:

- Publicar en su página de Internet, aplicación, plataforma o cualquier otro medio similar, en forma expresa y por separado, el impuesto al valor agregado correspondiente al precio en que se ofertan los bienes o servicios.

- Cuando cobren el precio y el impuesto al valor agregado correspondiente a las operaciones de intermediación por cuenta del enajenante de bienes, prestador del servicio u otorgante del uso o goce temporal de bienes, deberán:

- Retener a las personas físicas que enajenen bienes, presten servicios o concedan el uso o goce temporal de bienes, el 50\% del impuesto al valor agregado cobrado.

- Enterar la retención mediante declaración electrónica a más tardar el día 17 del mes 
siguiente.

- Expedir a cada persona física a la que le hubiera efectuado la retención un comprobante fiscal digital por Internet de Retenciones e información de pagos.

- Inscribirse en el Registro federal del contribuyente como personas retenedoras.

- Proporcionar al Servicio de Administración Tributaria la información que se lista a continuación de sus clientes enajenantes de bienes, prestadores de servicios u otorgantes del uso o goce temporal de bienes, en cuyas operaciones hayan actuado como intermediarios:

○ Nombre completo o razón social.

- Clave en el registro federal de contribuyentes.

- Clave única de registro de población.

○omicilio fiscal.

- Institución financiera y clave interbancaria estandarizada en la cual se reciben los depósitos de los pagos.

- Monto de las operaciones celebradas con su intermediación durante el período de que se trate.

O Tratándose de servicios de hospedaje, la dirección del inmueble.

○ Con la obligación de presentarla mensualmente a más tardar el día 10 del mes siguiente de que se trate.

Por otro lado, para entender las retenciones a realizar al artículo 18-J en su fracción dos nos dice que los prestadores de este servicio aplicables para esta sección deberán retener el 50\% del IVA cobrado. Ahora bien, si estas personas físicas no proporcionan al prestador del servicio su clave de RFC la retención deberá ser del 100\% y el retenedor sustituirá al enajenante, en el monto correspondiente a la retención. 
También, los contribuyentes personas físicas que hayan obtenido ingresos hasta por $\$ 300,000.00$ en el ejercicio inmediato anterior podrán ejercer la opción del artículo 18-M del cual hablaremos más adelante, siempre y cuando no reciban ingresos por otros conceptos de salarios y en general por la prestación de un servicio personal subordinado o por intereses. Los contribuyentes que inicien actividades podrán aplicar lo dispuesto anteriormente cuando sus ingresos no estimen los trecientos mil pesos mexicanos. Cuando en su primer ejercicio realicen operaciones por un período menor a doce meses, para determinar el monto, dividirán los ingresos obtenidos entre el número de días que comprenda el período y el resultado se multiplicará por 365 días. Si el resultado excedo los $\$ 300,000.00$ no se podrá tomar el beneficio del que hablaremos.

Ahora bien, los contribuyentes pueden optar por considerar la retención del artículo 18-J Fr. II como definitiva cuando las personas a que se refiere el citado artículo les haya efectuado la retención por la totalidad de las actividades realizadas con su intermediación o también pueden ejercer la siguiente opción:

Artículo 18-M. - ...podrán ejercer la opción cuando por las actividades celebradas con la intermediación de las personas a que se refiere el artículo 18-J de esta Ley, el cobro de algunas actividades se haya realizado por dichas personas y otras directamente por el contribuyente, siempre que en este último caso el contribuyente presente una declaración mensual por los cobros de las contraprestaciones realizados directamente, aplicando una tasa del $8 \%$.

Conviene subrayar que los que ejerzan la opción mencionada estarán obligados a lo siguiente:

\section{Figura 1}


Aceptaciones ante la opción del Art. 18-M

Expediran un CFDI a a los adquirentes de bienes o servicios..

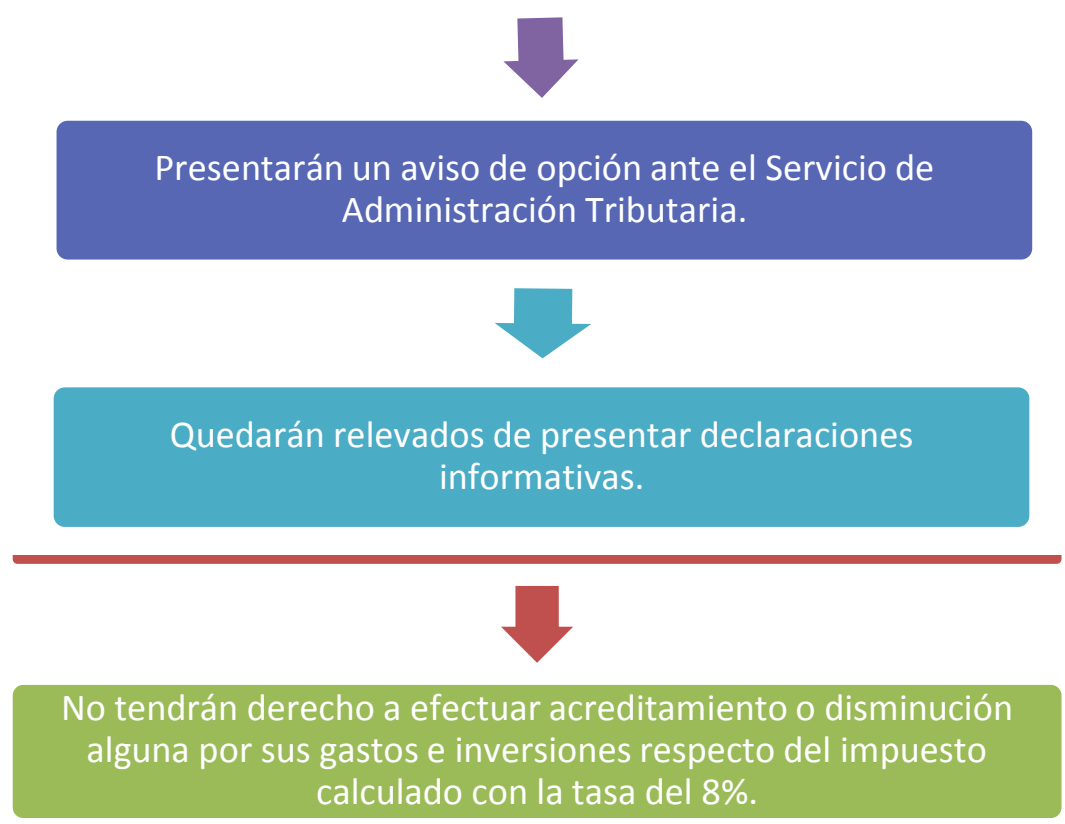

Conservarán el comprobante fiscal digital por Internet de

retenciones e información de pagos que les proporcionen las

personas que les efectuaron la retención del IVA

Fuente: Elaboración propia (2020).

Una vez ejercida la opción de aplicar la tasa de retención del 8\%, ésta no podrá variarse durante el período de cinco años contados a partir de la fecha en que el contribuyente haya presentado el aviso de opción ante el SAT.

\section{PRINCIPALES HALLAZGOS O CONCLUSIONES}

En cuanto a lo abordado anteriormente, es posible indicar que es obligación de las plataformas digitales pagar impuestos por una cuestión de equidad, ya que resulta injusto que algunas de las empresas más ricas del mundo no estén pagando impuestos. 
En este sentido, el nuevo marco cubre cuatro vertientes del modelo de negocio:

La descarga o acceso a imágenes, películas, texto, información, video, audio, música y juegos, incluyendo los de azar. Categoría en la que entran plataformas de streaming como Netflix. La descarga o acceso a libros, periódicos y revistas no está incluida en el modelo.

Los de intermediación entre terceros que ofrecen bienes o servicios a los demandantes de estos, en cuyo caso entran empresas como Uber y Amazon.

Clubes en línea y páginas de citas.

La enseñanza a distancia.

Tenemos que tener en cuenta que no se trata de un impuesto nuevo ni de un impuesto digital, el IVA se creó en 1980. Evidentemente, la ley original no contemplaba servicios digitales como Netflix o Uber. Por eso, se creó un nuevo esquema en el que estas empresas deben pagar impuestos, no se trata de un aumento en las tasas.

Este 1 de junio entraron en vigor las disposiciones transitorias de la Ley del Impuesto al Valor Agregado (IVA) para los servicios digitales. Entre otras cosas, estos cambios implican que algunas plataformas añadieron la incorporación del IVA (16\%) a la tarifa normal. Pese a ello, surgen dudas de quién pagará estos impuestos para las cuales mencionamos que son los usuarios quienes terminan pagando estos montos.

En el título II también hablamos del ISR y de igual manera que en el IVA a partir del 1 de junio de este año las personas físicas con actividades empresariales que enajenen bienes o presten servicios a través de internet, mediante plataformas tecnológicas, aplicaciones informáticas y similares, que participen en la oferta y demanda de bienes y servicios proporcionados por terceros, deberán pagar ISR por los ingresos mediante retención que efectuarán las personas morales residentes en México o residentes en el extranjero con o sin establecimiento permanente en el país, así como las entidades o figuras jurídicas extranjeras que proporcionen, de manera directa o indirecta, el uso de las citadas plataformas tecnológicas, aplicaciones informáticas y similares. Esta retención la efectuarán las 
plataformas a los prestadores de servicios; es decir, de los ingresos que obtengas por estos servicios la plataforma te descontará un porcentaje.

\section{REFERENCIAS}

Andares, V. (2017). Qué significa: Servicio Digital. Puebla, Puebla: Ediciones Península.

Mendoza, G. (2018). "El funcionamiento del comercio electrónico, categorías seguridad para usuarios y demografía de usos habituales." Teses de licenciatura, UAEM, Ecatepec, Edo. De México.

Molina, M. (2020). "The establishment of VAT in Mexico: A Political-economic Problem, 1968-1980: America Latina En La Historia Economica” Utah, EUA.

Moren, F. (2019). El impuesto digital en el mundo. Santurce, Puerto Rico: Ediciones Martínez Roca.

Ramirez, C. (2016). Impuesto al Valor Agregado Seminario Fiscal 2016. Ciudad de México: MGI.

Reyes, E. (2020). La última palabra en impuestos digitales la tendrá la OCDE. Recuperado el 18 julio de 2020, Grupo Expansión: https://expansion.mx/tecnologia/2020/05/26/la-ultima-palabra-en-impuestosdigitales-la-tendra-la-ocde

Riquelme, R. (2019). ¿Qué es el impuesto digital propuesto por legisladores en México? Recuperado el 14 de Julio de 2020, Periódico El Economista:https://www.eleconomista.com.mx/tecnologia/Que-es-el-impuestodigital-propuesto-por-legisladores-en-Mexico-20181015-0034.html

Seoane, E. (2005). La nueva era del comercio electrónico: Historia del comercio electrónico. Ciudad de México: Vigo. 